\title{
LETTERS
}

\section{Ensuring Indigenous participation in research on the health and well-being of Indigenous Peoples}

Dr. Janet Smylie and Wanda PhillipsBeck $^{1}$ raise a number of valid issues in their CMAJ commentary on Indigenous maternity care. We would like to highlight 2 of these. First, the challenges that Indigenous Peoples face need to be understood in the context of the harms of residential schools, the Sixties Scoop, and the ongoing inequities and systemic racism they continue to experience. Second, that in the era of Truth and Reconciliation, research exploring the health and well-being of Indigenous Peoples should include those peoples in all phases of the research. This fundamental requirement should ensure the ethical conduct of the research and appropriate interpretation of the findings. As leaders at the Manitoba Centre for Health Policy, we fully endorse this approach.

Although we have not been able to recruit Indigenous scientists to lead research studies focused on Indigenous populations as of yet, we partner with
Nanaandawewigamig (the First Nations Health and Social Secretariat of Manitoba), other First Nations groups (e.g., Swampy Cree Tribal Council) and the Manitoba Metis Federation in respectful partnerships. We have personally found these relationships to be opportunities for growth and new understanding. They have without question enhanced the quality of our research.

All research at the Manitoba Centre for Health Policy is subject to review by the Health Research Ethics Board at the University of Manitoba, the Health Information Privacy Committee of the Manitoba government and the custodians of the data included in the study. WallWieler and colleagues' study ${ }^{2}$ was approved by the data providers (the Ministry of Families) as well as these 2 committees. As a trainee, Wall-Wieler followed the processes required of her. The criteria used for approval do not, however, meet the standard described by Smylie and Phillips-Beck. To address this gap, the Manitoba Centre for Health Policy is in the process of working with its partners to institute an internal procedure to ensure all research conducted with data housed at the Manitoba Centre for Health Policy meets the highest ethical standards.

\section{Alan Katz MBChB MSc}

Director, Manitoba Centre for Health

Policy; professor, Departments of

Community Health Sciences and Family

Medicine, Max Rady College of Medicine, Rady Faculty of Health Sciences,

University of Manitoba, Winnipeg, Man.

\section{Marni Brownell PhD}

Associate director, Manitoba Centre for Health Policy; professor, Department of Community Health Sciences, Max Rady College of Medicine, Rady Faculty of Health Sciences, Winnipeg, Man.

Cite as: CMAJ 2019 June 24;191:E714. doi: $10.1503 / \mathrm{cmaj} .72120$

\section{References}

1. Smylie J, Phillips-Beck W. Truth, respect and recognition: addressing barriers to Indigenous maternity care. CMAJ 2019;191:E207-8.

2. Wall-Wieler E, Kenny K, Lee J, et al. Prenatal care among mothers involved with child protection services in Manitoba: a retrospective cohort study. CMAJ 2019;191:E209-15.

Competing interests: None declared. 